\title{
Correlation between tribological measurements and surface characteristics of HVOF coated steel and PTFE materials in sliding contact
}

\author{
B. Fernandez-Diaz ${ }^{1}$, M. Conte $^{1}$, A. Igartua ${ }^{1}$, X. Fernandez ${ }^{1}$, \\ G. Mendoza ${ }^{1}$ \& A. Straub ${ }^{2}$ \\ ${ }^{1}$ Manufacturing Processes Department, Tribology Unit, Tekniker, Spain \\ ${ }^{2}$ Landing Gear Division, Liebherr, Aerospace Lindenberg Gmbh, \\ Germany
}

\begin{abstract}
In recent years, several improvements have been made concerning the wear of materials in sliding contact, thanks to the employment of $\mathrm{Cr}^{+6}$-free hard coatings, their optimization, and the development of new deposition techniques and technologies. When solid lubricants, such as PTFE materials, are involved as sliding surfaces against steel material, roughness and hardness effects on friction and wear have to be taken into consideration, because they play an important role from the tribological stand point.

The aim of this work is correlation of tribological measurements with surface characteristics, in particular coating material, roughness and hardness of a landing gear rod sealing system. A cylinder-on-flat specimen configuration was chosen in order to faithfully reproduce working conditions, using a coated steel cylinder sliding against PTFE samples. The PTFE material was homogeneously worn independently of the countermaterial/coating, while when sliding against the softer material, the wear of the rod was observed. A comparison between results previously obtained on NBR is provided.
\end{abstract}

Keywords: friction, wear, PTFE, seals, $\mathrm{Cr}^{+6}$-free, coatings, $\mathrm{HVOF}$. 


\section{Introduction}

Friction and wear reduction is one of the main objectives in sliding mechanical parts for minimizing loss of energy and improving systems performance. In recent years, attention has also grown in respect of maintenance cost savings, therefore a key question is how to achieve low levels of friction, as well as high wear resistance. In the field of elastomeric seals several approaches have been used, such as changing the system configuration, designing new cross section shapes [1-3], texturing the contact surface and applying coatings. Furthermore, in 1979 Gent et al. [5] studied the wear of metal by rubber attributing those phenomena at the direct attack upon metals of free radical species generated by mechanical rupture of elastomer molecules during abrasion. It is suggested that such studies might lead to new metal finishing processes and surface treatment that can have the double effect of improving the tribological performances and giving protection from external agents. Furthermore, coating technology is gaining ground thanks to new available technologies and focusing in particular on the need to use new alternative non toxic surface treatment with at least the equivalent functionality of $\mathrm{Cr}^{+6}$. In a previous work the authors [4] tested the tribological behaviour of several $\mathrm{Cr}^{+6}$-free hard coatings applied by $\mathrm{HVOF}$ (High Velocity Oxy-Fuel) sliding against polymeric samples, observing the strong influence of the cylindrical counterbody: the higher the cylinder hardness, the lower the wear resistance of the elastomeric samples. Evidences of abrasion, melting and adhesion were found with the hardest coatings. On the other hand, the rods with lower hardness were observed suffering the strongest wear when tested against the hardest rubbers. A deeper investigation is herein proposed, taking into account the previous researches carried out, considering the PTFE material sliding against the same materials and coating previously tested and the same working conditions in order to clarify the influence of the surface characteristics on the tribological measurements.

\section{Experimental setup and specimens}

In the test rig in Figure 1, a filled-PTFE sample obtained from a commercial seal used in actual application (1) is mounted in an AeroShell Fluid 41 oil bath (2) and loaded by an axially sliding rod (3), supported and fixed by two holders (4) on which a normal constant load is applied and transmitted to the axel of the rod. The holders and a couple of screws avoid rotation of the rod around its axel. The system is located in a climate chamber in order to set the temperature and humidity percentage. The normal load was set on $50 \mathrm{~N}$ for the firsts $30 \mathrm{~s}$ and then at $100 \mathrm{~N}, 25 \mathrm{~Hz}$ frequency and $2 \mathrm{~mm}$ stroke for each sample (see Figure 1). The coefficient of friction $(\mathrm{CoF})$ was recorded at the regime condition for 30 minutes; each test was repeated 2-3 times.

The viscoelastic deformation and its effect on friction force were considered negligible in comparison to the other components due to the presence of fillers 


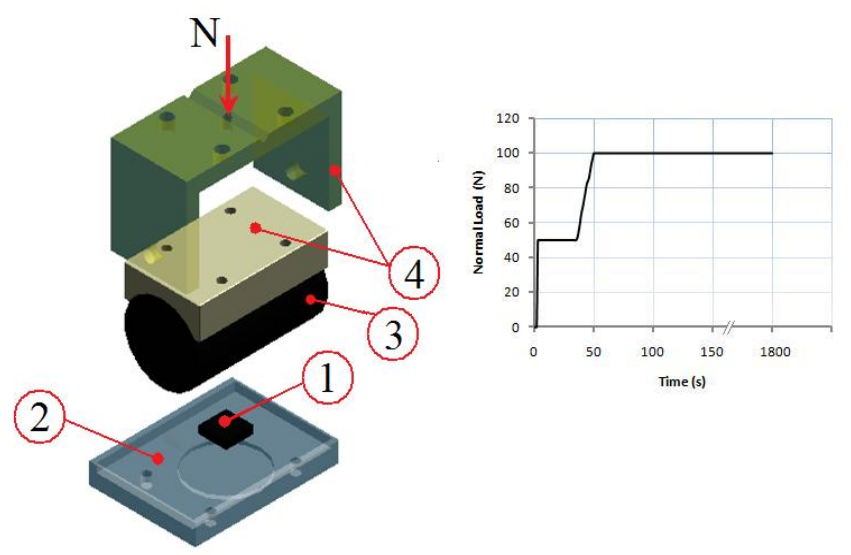

Figure 1: $\quad$ Test rig scheme and load history.

Table 1: $\quad$ Surface characteristics of coated rods.

\begin{tabular}{|c|c|c|c|}
\hline Rod material and treatment & $\begin{array}{c}\text { Coating } \\
\text { method }\end{array}$ & $\begin{array}{c}\text { Hardness } \\
(\mathrm{HV})\end{array}$ & $\mathrm{Ra}(\mu \mathrm{m})$ \\
\hline $\mathrm{AlBr}+\mathrm{G}$ & HVOF & 260 & 0,22 \\
\hline $\mathrm{AlBr}+\mathrm{G}+\mathrm{F}$ & HVOF & 260 & 0,04 \\
\hline Uncoated $+\mathrm{G}$ & - & 350 & 0,09 \\
\hline $\mathrm{NiCrBSi}+\mathrm{G}$ & HVOF & 745 & 0,16 \\
\hline $\mathrm{NiCrBSi}+\mathrm{G}+\mathrm{F}$ & HVOF & 745 & 0,04 \\
\hline $\mathrm{Cr}+\mathrm{G}$ & Electr. Bath & 850 & 0,20 \\
\hline $\mathrm{WCCoCr}+\mathrm{G}$ & HVOF & 1115 & 0,23 \\
\hline $\mathrm{WCCoCr}+\mathrm{G}+\mathrm{F}$ & HVOF & 1115 & 0,03 \\
\hline $\mathrm{CrN}+\mathrm{G}$ & PVD & 1974 & 0,19 \\
\hline $\mathrm{ZrN} / \mathrm{ZrCN}+\mathrm{G}$ & PVD & 1975 & 0,16 \\
\hline
\end{tabular}

(such as glass fibres, graphite and bronze), which are able to improve the mechanical characteristics of PTFE. Furthermore, no appreciable plastic deformation was observed.

Three different technologies were used for coating the steel rods: High Velocity Oxy-Fuel (HVOF), Electrolytic Bath and Physical Vapour Deposition (PVD). Subsequently the coated rods were exposed to different surface modification processes $(\mathrm{G}=$ Grinding, $\mathrm{F}=$ Superfinishing) to vary their texture. Vickers Hardness and roughness $(\mathrm{Ra})$ have been measured and reported in Table 1.

The shot peening process was also applied to the rod with the aim of changing the texture of the surface and not to produce a compressive residual stress layer, modifying the mechanical characteristics of the metal. It was associated with 
grinding process to reduce the amount of induced-roughness peaks, but no relevant results were found. Therefore, they were not reported.

\section{Results and discussion}

Taking into consideration as reference the uncoated and Chromium coated by electrolytic bath rods $\mathrm{CoF}$, applying grinding surface treatment to the rods coated by means of the HVOF process did not result in a clearly defined trend at any level of hardness (Figure 2). Uncoated material with grinding resulted from having better roughness $(\mathrm{Ra})$ than the coated and grinded ones; therefore it was decided to also apply a finishing process to the coated cylinders, obtaining lower values of $\mathrm{Ra}$ and subsequently relevant improvement in terms of $\mathrm{CoF}$, especially for the hardest coating. The shot peening process seemed to have no notable effects on the CoF. In general, the grinded+finished rods improve their CoF with hardness, while grinding alone had no relevant effect. PVD coatings of $\mathrm{CrN}$ and $\mathrm{ZrN} / \mathrm{ZrCN}$ were also tested, also showing considerable improvements in comparison with the results obtained by the authors [4] on NBR specimens.

The effect of finishing treatment on the $\mathrm{CoF}$ is the opposite of that seen by the authors for NBR materials [3], independently of rod hardness, demonstrating that NBR has less ability to form a transfer film on the counterface, resulting in friction force increment (Figure 3). The $\mathrm{CoF}$ is more influenced then by roughness than by PTFE. A relevant difference between NBR rubber and PTFE can be observed in terms of friction at the initial stage of the test, when the high degree of lateral mobility of PTFE chains quickly induces molecular orientation in the sliding direction. This phenomenon is also aided by PTFE's smooth linear molecular profile and the ability of the electron clouds of the large fluorine ions to screen the bonding forces between neighbouring molecules.

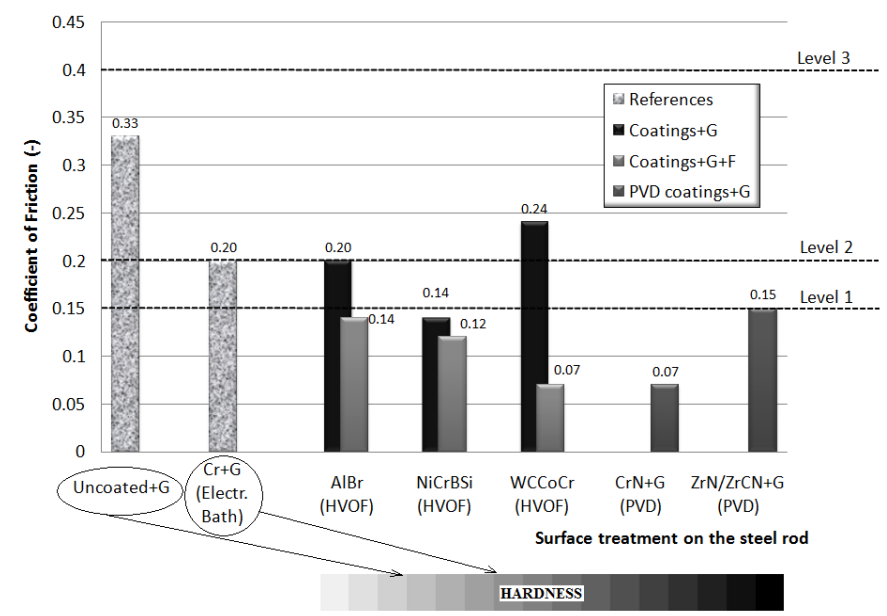

Figure 2: $\quad$ Coefficients of friction $(\mathrm{CoF})$. 


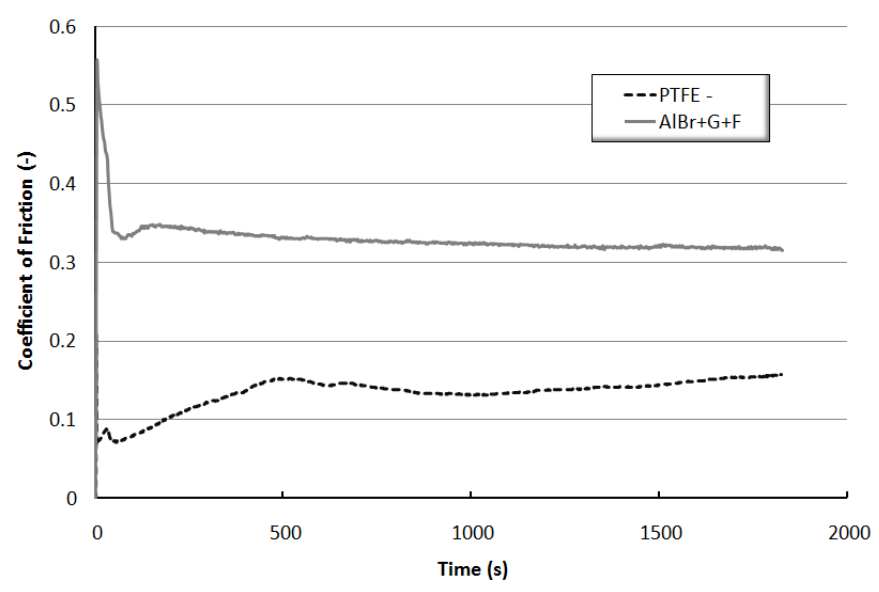

Figure 3: Comparison between PTFE/NBR against the $\mathrm{CoFs}$ of $\mathrm{AlBr}+\mathrm{G}+\mathrm{F}$ rods.

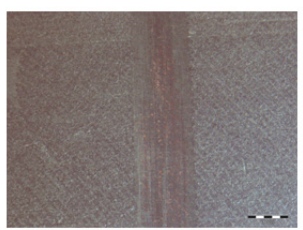

$\mathrm{AlBr}+\mathrm{G} 260 \pm 10 \mathrm{HV} \mathrm{Ra}:$

$0.22 \mathrm{~mm}$

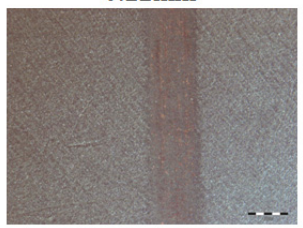

$\mathrm{AlBr}+\mathrm{G}+\mathrm{F} 260 \pm 10 \mathrm{HV}$ Ra: $0.04 \mathrm{~mm}$

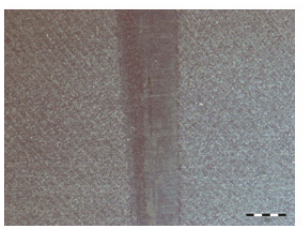

$\mathrm{NiCrBSi}+\mathrm{G} 745 \pm 15 \mathrm{HV}$

Ra: $0.16 \mathrm{~mm}$

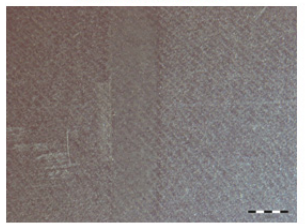

$\mathrm{NiCrBSi}+\mathrm{G}+\mathrm{F} 745 \pm 15 \mathrm{HV}$

Ra: $0.04 \mathrm{~mm}$

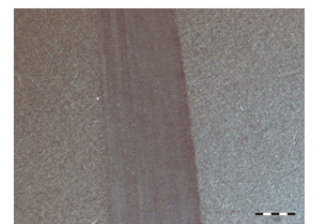

$\mathrm{WCCoCr}+\mathrm{G} 1115 \pm 92 \mathrm{HV}$

Ra: $0.23 \mathrm{~mm}$



$\mathrm{WCCOCr}+\mathrm{G}+\mathrm{F}$

$1115 \pm 92$ HV Ra: $0.025 \mathrm{~mm}$

Figure 4: Wear of PTFE specimens.

Wear on PTFE specimens was observed and quantified: qualitatively, very similar wear mechanisms were observed independently of countersurface materials, coating, texture and hardness as can be seen for the example in Figure 4. The PTFE material was worn homogenously and the ploughing effect of the counterbody provoked defined wear scars. It seemed it was not able to form a thick transfer film on the countersurface and melting of the material did not occur.

Adhesion of particles was observed only when sliding against the AlBr rods: these surface films result from points on the PTFE and countersurface being brought into adhesive contact with subsequent sliding (Figure 5). 




Figure 5: $\quad$ Adhesion of particles.

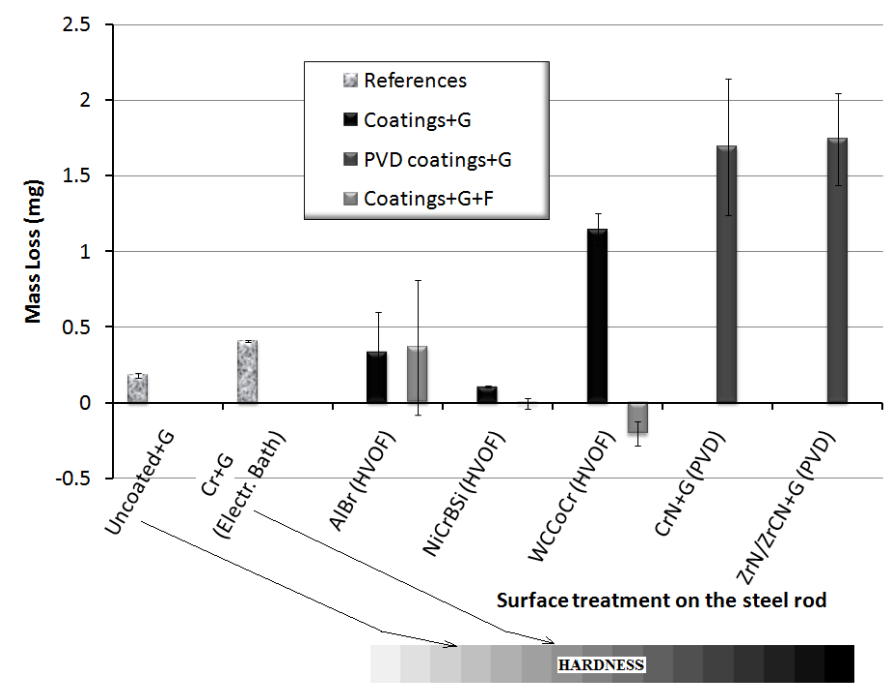

Figure 6: PTFE mass loss.

As can be seen in Figure 6, the higher wear on the PTFE samples is obtained when sliding against the hardest counterbodies.

On increasing the sliding displacement, PTFE fibrils broke along their length, leaving a fragment running along the surface, as well as being transferred to the countersurface, oriented along the sliding direction. Such fragments fractionally cover the countersurface filling in the roughness valleys to form a transfer film; the phenomenon, deeply explained in [5] for natural rubber sliding against metals, came out also for the PTFE material attacking the most reactive coatings (AlBr), independently of the surface finishing process applied. In fact, a transference film was found and consequently a chemical reaction film was formed on the steel surface. The other rods suffered just light surface polishing, also due to their higher hardness, as seen for example in Figure 7. 


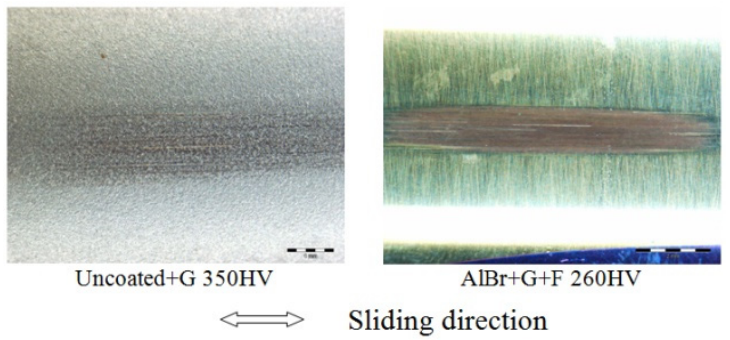

Figure 7: Wear of the rods' surface by PTFE.

\section{Conclusions}

A correlation of tribological measurements with surface characteristics, in particular coating material, roughness and hardness of a landing gear rod sealing system, was carried out. The finishing treatment effect on the CoF was observed to be the opposite of that met previously for NBR material, independently of rod hardness, as a demonstration that NBR has less ability to form a transfer film on the counterface, resulting in friction force increment. A relevant difference between NBR rubber and PTFE was observed in terms of the CoF at the initial stage of the test when the high degree of lateral mobility of PTFE chains quickly induces molecular orientation in the sliding direction.

Very similar wear mechanisms were observed independently of countersurface materials, coating, texture and hardness: the PTFE material was worn homogenously and the ploughing effect of the counterbody provoked defined wear scars. Just some spare particles were observed on the countersurface and melting of the material did not occur. The adhesion of particles was observed only when sliding against the $\mathrm{AlBr}$ rods: these surface films result from points on the PTFE and countersurface being brought into adhesive contact with the subsequent sliding.

\section{Acknowledgements}

The authors are grateful to all the partners of the KRISTAL (Knowledge-based Radical Innovation Surfacing for Tribology and Advanced Lubrication) and FUNDTRIBO (Fundamentals of Tribology - Correlation between Wear Characteristics and Material Properties of Polymers Ranged from Sub-Micro to Macro Scale) projects and the European Commission for their support.

\section{References}

[1] Calvert, C., Tirovic, M., Stolarski, T., Design and development of an elastomer-based pneumatic seal using finite element analysis. Journal of Engineering Tribology, 216(J3), pp. 127-138, 2002 
82 Tribology and Design

[2] Belforte, G., Manuello, A., Mazza, L., Optimization of the Cross Section of an Elastomeric Seal for Pneumatic Cylinders. Journal of Tribology, 128, pp. 406-413, 2006

[3] Conte, M., Interaction between seals and counterparts in pneumatic and hydraulic components. PhD Thesis, Turin, Italy, June 4th, 2009

[4] Fernandez-Diaz, B., Igartua, A., Fernandez, X., Mendoza, G., Straub, A., Tribological study of alternative CrVI-free hard coating sliding against polymers. Proceeding of the World Tribology Congress 2009, Kyoto, Japan, 2009

[5] Gent, A. N., Pultorf, C. T. R., Wear of metal by rubber. Journal of Material Science, 14, pp. 1301-1307, 1979 